\title{
Improving Joint Attention in Children with $\cong$ Autism: A VR-AR Enabled Game Approach
}

\author{
Soumik Sarker, Ali Hasan Md. Linkon, Faisal Haque Bappy, Md Forhad Rabbi, Md Mahadi \\ Hasan Nahid
}

\begin{abstract}
Autism Spectrum Disease (ASD) can be referred to as one type of neurodevelopmental disorder, causing communication or behavioral disabilities in multiple severity levels. These challenges cause difficulties in communication, interaction, problem-solving, etc. Though having no persistent cure for ASD, several treatments and intervention strategies prevail for their behavioral development. These treatments include social skill training, sensory integration, and occasional therapy, etc. Many of these researches highly emphasize joint attention, which is the common issue of most autism cases. Joint or shared attention is highly essential for language and communication skill development. In this work, we proposed a game-based approach to improving the joint attention of children with autism. This approach focuses on the efficiency of skilling up their shared attention by interacting with digital models through problem-solving. We integrate AR (Augmented Reality) and VR (Virtual Reality) technologies for solving this issue. Using these technologies, we have designed an interactive multi-staged game module, including several types of real-life alike problems. Problem-solving and interacting with these mascots can help children build up learning and communication skills, which sometimes real-life interaction may find challenging. Again, eye screening and health can be issues in the device-centric scheme. An analytical survey has been presented in this work, confirming that all these health issues have been carefully considered. Implementation and outperforming results of this work will give a clear stand about the effectiveness of this module. Besides, we present sufficient analytics confirming that this module can also be efficient for normal children.
\end{abstract}

Keywords: Autism Spectrum Disease (ASD), AR (Augmented Reality), HCI, Joint Attention, VR (Virtual Reality)

\section{INTRODUCTION}

From the social perspective of Bangladesh, autism is not considered a severe medical issue, and in most cases, people with autism do not receive any thorough medical treatment. ASD has a high percentage of occurrence in children, affecting 1 in 160 subjects [1]. According to the World

Manuscript received on January 27, 2021.

Revised Manuscript received on February 10, 2021.

Manuscript published on February 28, 2021.

* Correspondence Author

Soumik Sarker*, Department of CSE, Shahjalal University of Science and Technology, Sylhet, Bangladesh

Ali Hasan Md. Linkon, Department of CSE, Shahjalal University of Science and Technology, Sylhet, Bangladesh

Faisal Haque Bappy, Department of CSE, Shahjalal University of Science and Technology, Sylhet, Bangladesh

Md Forhad Rabbi, Department of CSE, Shahjalal University of Science and Technology, Sylhet, Bangladesh

Md Mahadi Hasan Nahid, Department of CSE, Shahjalal University of Science and Technology, Sylhet, Bangladesh

(C) The Authors. Published by Blue Eyes Intelligence Engineering and Sciences Publication (BEIESP). This is an open access article under the CC BY-NC-ND license (http://creativecommons.org/licenses/by-nc-nd/4.0/)
Health Organization supported survey 2009, there are 0.84\% of children suffering from Autism Spectrum disorders. Children with autism cannot interact with normal people, in fact, with their kins, and they often become the victim of bullying. The current education procedure for autistic children has several flaws. This research represents a game-based approach for improving the joint attention of autistic children through several strategic problem-solving phases, which is the core term of concern in the field of autism. Joint or shared attention means the ability to share a focus on something with others. Several research pieces amplify the importance of joint attention skills for autism and proposed therapy or treatment schemes for the betterment of their joint attention. We implemented VR-AR approaches to make it more interactive. We have also built a prototype to test the efficiency of the proposed approach. Mobile screening and health issues have also been checked with sheer attention, as we involve several gadgets. By reviewing several approaches related to this domain, we think this approach can be unique and useful for bettering autistic people.

\section{RELATED WORK}

According to the World Health Organization supported survey 2009, there are $0.84 \%$ of children suffering from Autism Spectrum disorders. Against this magnitude of disease burden, only 200 psychiatrists and a limited number of other health professionals are serving the nation [2] Several previous studies have shed light on betterment approaches for autistic people. White et al. review most of the state of research studies regarding social skill development for autistic children [3]. Dillenburger et al. claim ABA (Applied Behaviour Analysis) can be an effective form for the parents to nursing autistic children [4]. They also presented a questionnaire-based report to validate its impact. Myers et al. present a clinical report reviewing the primary treatment and educational strategies for autism spectrum disease [5]. They showed clear guidelines for the pediatricians with supported interventions regarding ASD. Steiner et al. emphasize parent education programs for nursing their autistic children. Koegel et al. claim that self-management can be a useful technique for bettering responsiveness [6]. Swaggart et al. propose that social stories can impact developing social behavior with children with autism [7]. From the technical logistics perspective, we also find relevant research in this domain. This paper [8] presents a review regarding potential virtual reality-based schemes probed for the betterment of autistic children. 
The author of this paper [9] presents logistics claiming virtual reality can be appreciable for both autistic and average children's educational purposes. We believe our strategic game-based approach can be useful in this domain by reviewing this previous research.

\section{METHODOLOGY}

This paper's core goal is to represent an interactive learning app for nursing the mental health of autistic children by improving their joint attention. As explained earlier, improving the joint or shared attention is the core concern of the existing therapies or treatments. We try to create an interactive environment through which he or she feels comfortable solving the task. By solving these tasks, they can increase their attention to a particular topic and enhance their other social skills. We implemented our methodology as an android app and ran some simulations to judge our scheme's output. Along with the children learning phase, we also focus on some other critical issues. Some of them are stated below-

- Eye Screening: As our module has essential facts on the VR module, the VR interface's eye impact cannot be irreplaceable. Our first and foremost concern was designing such a VR module so that it suits eye comfort.

- Specialized UI: As the system is supposed to serve special children, we have to focus on such a GUI that can grow their attention.

\section{IMPLEMENTATION}

As the implementation of our methodology, we developed an android application entitled- Ongkur. We designed our app in three segments to serve three age-sectioned autistic people.

\section{Phase: KURI}

In this Kuri phase, we create interactive VR mascots like a fox, panda. User can choose any of the mascots as he/she wants. The user will then be tasked with various kinds of assignments like feeding the mascot, comb its hair, or giving it a present. If the user successfully does the assignment, the mascot gets happier. Also, the users are tasked with different kinds of IQ tests, like choosing the right objects among various types of objects, drawing a particular item, etc. The user can see tutorials of making plane origami and drawing a plane using a VR box through our application. Then he/she is tasked to draw a plane on paper. After the drawing, his mentor took a photo of the paper, and using AR our app will judge how good the drawing is.

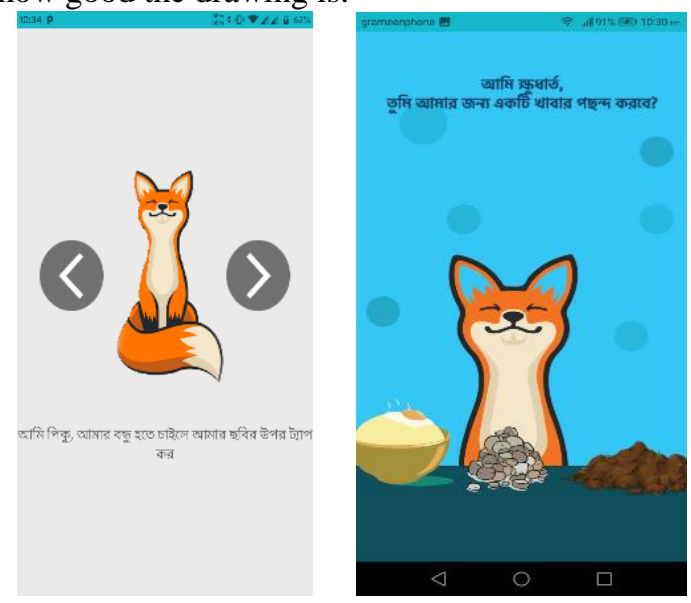

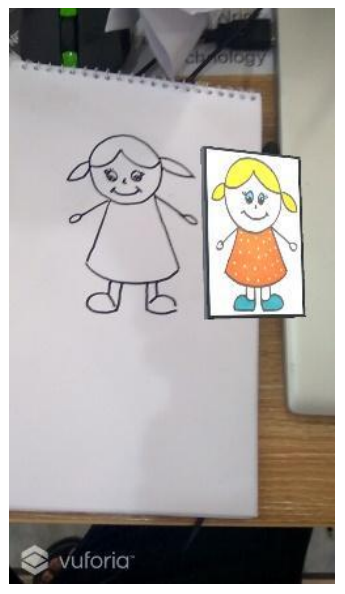

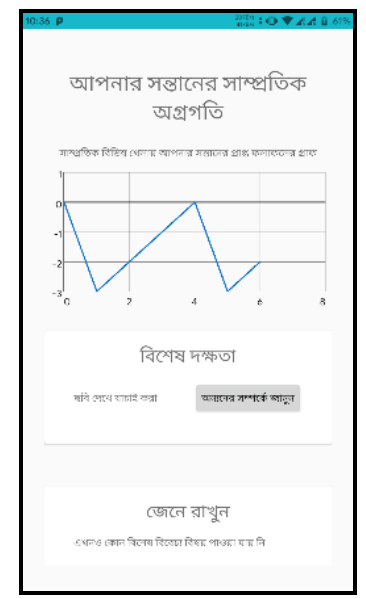

Fig 1. Some screenshots of the Android app Ongkur (Kuri Phase)

\section{Phase: Nobin}

This phase is a more advanced one. In this phase, the mascot will be replaced by human-like cartoons. In this phase, we try to connect the child with a virtual boy or a girl of his/her age. Thus, we try to unleash his/her capability to interact. This model tries to communicate with the user through different real-time events. For example, we designed a scene where the boy lost his way home, and he tries to communicate with a user and wants his /her help. So, the user is assigned to put on the VR box, find the boy, and make a way to his home. Thus, by solving this puzzle, we can enrich the level of attention of the autistic child as it is one of the main issues and build up his/her social interaction level.

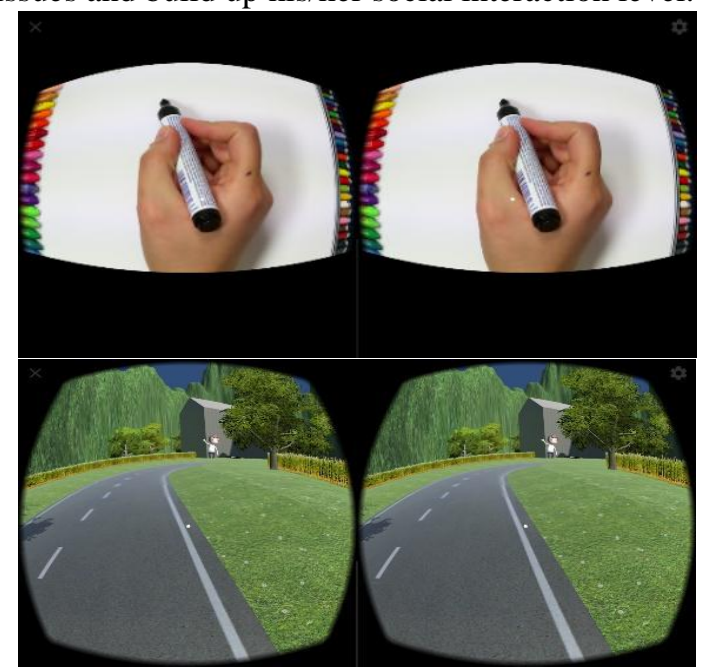

Fig 2. Some screenshots (VR) of android app Ongkur (Nobin Phase)

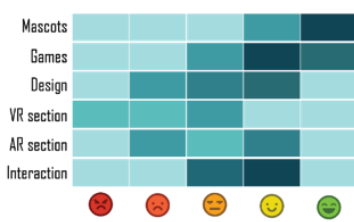

Child
Phase: Pushpa

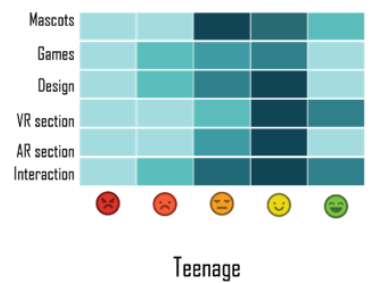

Teenage

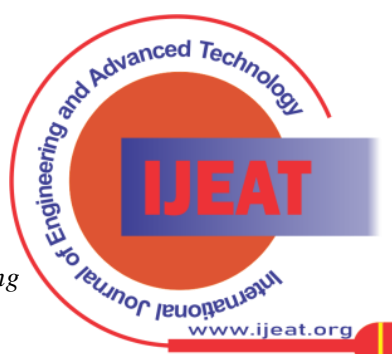

Published By:

Blue Eyes Intelligence Engineering and Sciences Publication

(C) Copyright: All rights reserved. 
We have planned this section for a more advanced case. We think about online AI-based chat apps for the advanced socialization of autistic people. We have planned to design an AI-based interacting impersonating model to give them a more practical feeling. This model will talk to the individual and react almost like a human. The audience of this section will be many aged autistic people. But due to the lack of data on aged autistic people, we cannot accumulate a satisfactory level of requirements for fulfilling this scheme.

\section{EXPERIMENTAL RESULT AND ANALYSIS}

After finishing the development of the prototype, we have gone through a small-scale survey for feedback. As an experimental approach, we first made some screening surveys for many people. Some of the survey portions are given below-

Table- I: Survey Questions

\begin{tabular}{|c|c|}
\hline Overall & $\begin{array}{l}\text { 1. Is the use of any gadget (Virtual Box) comfortable for autistic } \\
\text { children? } \\
\text { 2. Does the continued use of VR boxes create any optical } \\
\text { discomfort for autistic children? } \\
\text { 3. Is the system UI comfortable for them? }\end{array}$ \\
\hline $\begin{array}{l}\text { Kuri } \\
\text { Phase }\end{array}$ & $\begin{array}{l}\text { 1. Is the mascot concept effective? } \\
\text { 2. What about the regular basis test segment and game segment? } \\
\text { 3. Is the reward giving phase improves their emotion? }\end{array}$ \\
\hline $\begin{array}{l}\text { Nobin } \\
\text { Phase }\end{array}$ & $\begin{array}{l}\text { 1. Does the system gradually improve users' social interaction? } \\
\text { 2. Does the test segment really impact on next phase of } \\
\text { crowdsourcing? }\end{array}$ \\
\hline $\begin{array}{c}\text { Pushpa } \\
\text { Phase }\end{array}$ & $\begin{array}{l}\text { 1. Is the system solving social interaction between autistic } \\
\text { people? } \\
\text { 2. Are the crowdsourcing phase helps them to be self-employed? }\end{array}$ \\
\hline
\end{tabular}

From the feedback, we have changed some minor issues with the prototype. As our design approach is mainly featured with children, so the prototypical survey is mainly focused on children, especially those with autism. We try to figure out if the UX-UI is good enough for their interaction. We categorize the audience into four classes based on age. The below graph depicts an overall view of our audience distribution (in percentage):

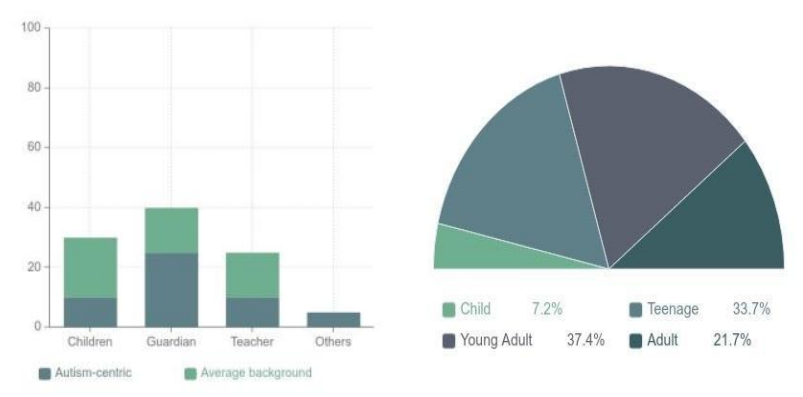

Fig 3. Overall view of audience distribution (in percentage)

So, after the quick survey and prototype-based fieldwork, we have received positive feedback from the audience. For each, we have shown them a walkthrough of our application in some cases with the use of VR boxes. Then we have gone through the questionnaire regarding the application and how it works.

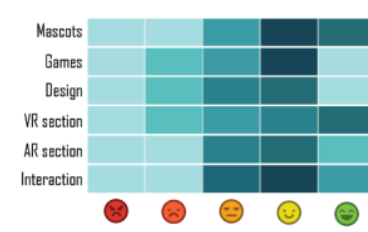

Young adult

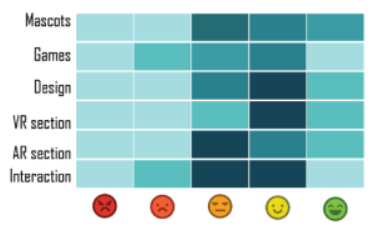

Adult
Fig 4. Overall review of our system \& survey

Here is a quick view of the overall review of this system summed up by the survey.

\section{DISCUSSION AND FUTURE DIRECTIONS}

We gathered information from a huge bucket of tested research before developing the modules' mechanism. First and foremost, we emphasized that no autistic children are the same \& each has specific strengths. The system first tries to identify these strengths through manual \&/or dynamic approaches. The ASD-affected often get sensory overloads \& are easily distracted. The VR module helps them be in a peaceful learning environment, which encourages activities in a non-threatening way. As it is easy for the ASD-affected to follow a routine, we provide a companion to remind them of their schedule. In return, this companion also works as a shadow-teacher who can comfort the child during a meltdown. The system is very visual, there are no abstract concepts, and long strings of words have been carefully avoided. The AR portion of the application prompts the child to perform real-life activities. These activities are, in turn, recorded and sent to the caregivers for manual calibration and alerts. We made sure there is no confrontation; instead, a child is gradually desensitized to a situation. We think the most innovative part of our system is incorporating data with the smart technologies we had hands-on. Besides this app-oriented approach, we have learned a few other things related to autism from our fieldwork. One of these fundamentals is Joint attention. All the strategies or therapy that has been used for leveraging autistic people are mainly focused on strengthening their joint attention. We are trying to explore the terms and backend from previous research works of joint attention and join our approach towards this path.

\section{CONCLUSION}

Throughout the workflow, we understand the necessity of such a module for the autistic child. At first, our concern was to build a generalized learning module with a playful mascot using VR to cope with the module without any health impact. According to the field visits, we tried to refinish the module to satisfy every aspect of the training procedure of the autistic child. We hope these modules will find profound significance in scaling up the joint attention of not only special but also average children.

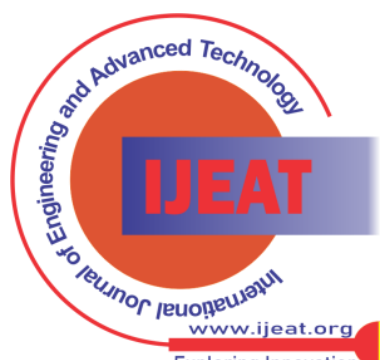




\section{ACKNOWLEDGMENT}

We would like to thank Shahjalal University of Science and Technology (SUST) and SUST Research Center for their support \& research grant.

\section{REFERENCES}

1. Patricia Mesa-Gresa, Hermenegildo Gil-Gómez, José-Antonio Lozano-Quilis and José-Antonio Gil-Gómez. Effectiveness of Virtual Reality for Children and Adolescents with Autism Spectrum Disorder: An Evidence-Based Systematic Review.

2. World Health Organization. (2007). WHO-AIMS report on mental health system in Bangladesh.

3. Williams White, S., Keonig, K. \& Scahill, L. Social Skills Development in Children with Autism Spectrum Disorders: A Review of the Intervention Research. J Autism Dev Disord 37, 1858-1868 (2007). https://doi.org/10.1007/s10803-006-0320-x

4. Maurice, C., Green, G., \& Luce, S. C. (Eds.). (1996). Behavioral intervention for young children with autism: A manual for parents and professionals. PRO-ED.

5. Myers, S. M., \& Johnson, C. P. (2007). Management of Children with Autism Spectrum Disorders. PEDIATRICS, 120(5), 1162-1182. doi:10.1542/peds.2007-2362

6. Koegel, L.K., Koegel, R.L., Hurley, C. and Frea, W.D. (1992) IMPROVING SOCIAL SKILLS AND DISRUPTIVE BEHAVIOR IN CHILDREN WITH AUTISM THROUGH SELF-MANAGEMENT. Journal of Applied Behavior Analysis, 25: 341-353. https://doi.org/10.1901/jaba.1992.25-341

7. Swaggart, B. L., Gagnon, E., Bock, S. J., Earles, T. L., Quinn, C., Myles, B. S., \& Simpson, R. L. (1995). Using Social Stories to Teach Social and Behavioral Skills to Children with Autism. Focus on Autistic Behavior, 10(1), 1-16. https://doi.org/10.1177/108835769501000101

8. Sarah Parsons \& Sue Cobb (2011) State-of-the-art of virtual reality technologies for children on the autism spectrum, European Journal of Special Needs Education, 26:3, 355-366, DOI: 10.1080/08856257.2011.593831

9. Pantelidis, V. S. (2010). Reasons to use virtual reality in education and training courses and a model to determine when to use virtual reality. Themes in Science and Technology Education, 2(1-2), 59-70.

\section{AUTHORS PROFILE}

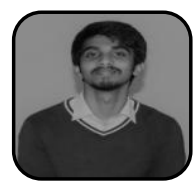

Soumik Sarker is an undergrad final year student and researcher at Shahjalal University of Science and Technology (SUST), Sylhet, Bangladesh. His research interest includes Blockchain, Cloud computing, and HCI.

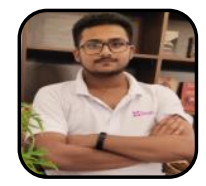

Ali Hasan Md. Linkon is an undergrad final year student and researcher at Shahjalal University of Science and Technology (SUST), Sylhet, Bangladesh. His research interests are Deep learning, Computer vision \& HCI.

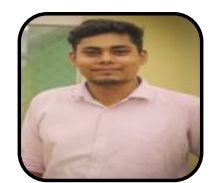

Faisal Haque Bappy is an undergrad final year student and researcher at Shahjalal University of Science and Technology (SUST), Sylhet, Bangladesh. His research interest includes Blockchain, Cybersecurity, and HCI.

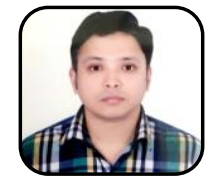

Dr. Md Forhad Rabbi is an associate professor a Shahjalal University of Science and Technology (SUST), Sylhet, Bangladesh. He completed his $\mathrm{PhD}$ in Computing, Curtin University, Australia. His research interests are Human-Computer Interaction, Software Engineering, Data Mining, ICT4D, Social Computing, E-Governance, and Machine Learning.

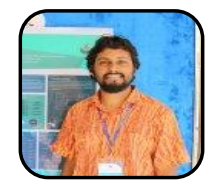

Md Mahadi Hasan Nahid is an assistant professor at Shahjalal University of Science and Technology (SUST), Sylhet, Bangladesh. His research interests are Machine Learning, Natural Language Processing, Big Data Analytics, Artificial Intelligence, and HCI.

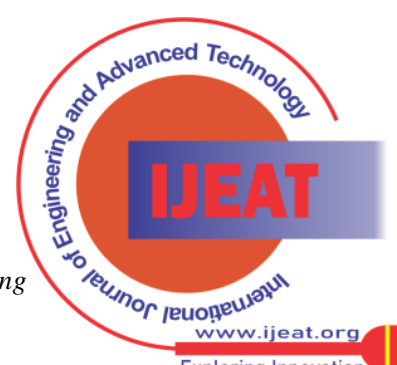

